\title{
Intraperitoneal distribution of alginate microcapsules in mice
}

\author{
F. Dagbert ${ }^{1^{\star}}$, Y. J. McConnell ${ }^{1,4}$, E. Carmona ${ }^{2}$, L. Sideris ${ }^{1}$, J. P. Hallé ${ }^{3}$, P. Dube ${ }^{1}$ \\ ${ }^{1}$ Department of Surgery, Hôpital Maisonneuve-Rosemont, Université de Montréal, Montréal, Canada; \\ *Corresponding Author: francois.dagbert@umontreal.ca \\ ${ }^{2}$ Maisonneuve-Rosemont Research Centre, Université de Montréal, Montreal, Canada \\ ${ }^{3}$ Department of Medicine, Hôpital Maisonneuve-Rosemont, Université de Montréal, Montréal, Canada \\ ${ }^{4}$ Division of Surgical Oncology, University of Calgary, Calgary, Alberta
}

Received 23 November 2013; revised 29 December 2013; accepted 15 January 2014

Copyright (C) 2014 F. Dagbert et al. This is an open access article distributed under the Creative Commons Attribution License, which permits unrestricted use, distribution, and reproduction in any medium, provided the original work is properly cited. In accordance of the Creative Commons Attribution License all Copyrights (c) 2014 are reserved for SCIRP and the owner of the intellectual property F. Dagbert et al. All Copyright (C) 2014 are guarded by law and by SCIRP as a guardian.

\section{ABSTRACT}

Introduction: Improved drug delivery mechanisms for the treatment of residual peritoneal cancer cells following cytoreduction surgery are needed. Alginate microcapsules are a potentially useful mechanism for delivery of bioengineered cells, but when injected into the peritoneum, their distribution and properties are not well described. Methods: Aliquots of 300,600 or 1200 microcapsules were injected into the peritoneum of 81 mice. Mice were sacrificed at 6,12 , 18 , and 48 days and laparotomy was performed to quantify the distribution of microspheres. Results: The injections were well tolerated for up to 48 days. No peritoneal adherence or inflammatory reaction was noted to the microcapsules. Injection of 1200 microcapsules resulted in a better overall persistence and widespread peritoneal distribution at up to $\mathbf{4 8}$ days. The volume of fluid used for injection of the microcapsules did not affect their distribution or persistence. Conclusion: The intraperitoneal injection of alginate microspheres allows wide and persistent distribution throughout the abdominal cavity. The next step is to test the distribution of microcapsules when delivered following surgery in a rodent model.

\section{KEYWORDS}

Alginate Microcapsule; Peritoneal Cavity;

Peritoneal Carcinosis; Thymidine

Phosphorylase; HIPEC; Capecitabine

\section{INTRODUCTION}

Cytoreduction surgery and heated intraperitoneal chemotherapy (CRS + HIPEC), combined with systemic chemotherapy for residual microscopic disease, are currently used to treat patients with peritoneal carcinomatosis from colorectal cancer (CRC). This therapeutic approach has a $20 \%$ - 30\% 5-year overall survival, but also has a $30 \%-35 \%$ major morbidity rate and $0 \%-4 \%$ perioperative mortality when conducted at experienced centres [1-4]. The proportion of this morbidity attributable to the HIPEC component is unknown but is thought to be substantial. Less toxic drug delivery methods are needed.

5 -fluorouracil (5-FU) is a chemotherapy agent used to treat CRC. 5-FU is cell-cycle specific and thus requires prolonged contact with tumor cells for best effect. It is a small molecule, and rapidly absorbed into the systemic circulation when administered into the peritoneum [5]. When administered intravenously, 5-FU is equally distributed to the peritoneal cavity and other body tissues. It remains in the peritoneum for longer time due to the lack of dihydropyrimidine dehydrogenase (DPD), the enzyme responsible for degradation of 5-FU, in that compartment [5]. However, prolonged intravenous 5-FU therapy is cumbersome for the postoperative patient.

Capecitabine is a once-daily oral prodrug currently indicated for metastatic CRC. The final step in its conversion to 5-FU requires thymidine phosphorylase (TP), an enzyme present in CRC cells at higher levels than in normal tissues or plasma [6-8]. However, the number of CRC cells remaining in the peritoneum after CRS is small and the cells are widely distributed. The effective treatment of these residual cells with capecitabine may require adjunctive measures to increase and prolong the 
amount of TP available in the peritoneum.

Prolonged higher levels of TP in the peritoneum may be created by implantation of bioengineered TP-producing cells. To avoid immunodestruction, such cells would require protection with a membrane such as alginatebased microcapsules. Alginate microcapsules have been studied in vivo for the delivery of cells producing insulin growth factor for the treatment of diabetes $[9,10]$. They function to protect encapsulated cells from the immune system, while allowing protein products to diffuse freely [10].

This study addresses the first step in the development of an alginate-microcapsule technology for delivering TP-producing cells to the peritoneum. It evaluates the anatomic distribution of empty alginate microcapsules, over time, after injection varying concentrations into the peritoneal cavity of mice.

\section{MATERIAL AND METHODS}

Empty alginate-poly-L-lysine-alginate (APA) microcapsules, each 300 um in diameter were created according to a published protocol and colored with dextran blue. (9) Microcapsules were counted, under the microscope, into 27 aliquots each of 300,600, or 1200 microcapsules. For each number of microcapsules, 9 aliquots each were mixed into $0.9 \%$ saline solution with a volume of $0.5,1.0$, or $2.0 \mathrm{~mL}$, respectively. Each aliquot in solution was injected into the peritoneal cavity of a mouse using a 22gauge needle In total, 81 mice of varying sex, age and breed were used. All mice were housed in a certified facility and the study protocol was approved by the institutional committee for the protection of laboratory animals.

For the 300- and 1200-microcapsule groups, for each concentration of microcapsules, 3 mice were sacrificed at each of 6, 12 and 18 days following injection, using carbon dioxide asphyxiation. For the 600-microcapsule group, 3 mice were sacrifice at each of 6,12 , and 48 days following injection, using carbon dioxide asphyxiation. This later sacrificed group was used to evaluate the development of intra-abdominal adhesions with longer term exposure.

For each mouse, immediately after sacrifice a midline laparotomy was performed. Any inflammatory reaction or peritoneal adhesions were noted. The peritoneal cavity was then examined under the microscope with a magnification of 8-30X, and the quantity and distribution of microcapsules in the abdomen was scored from 0 to 4 . Each quadrant of the abdomen was evaluated and an overall peritoneal microcapsule quantification (PMQ) score assigned (Table 1). All mice were evaluated by the same examiner. Mann-Whitney testing was used to evaluate differences between groups.
Table 1. Peritoneal microcapsule quantification scoring system.

\begin{tabular}{cl}
\hline Score & Description \\
\hline 0 & No microcapsules seen \\
1 & Microcapsules in 1 abdominal quadrant \\
2 & Microcapsules in 2 - 3 quadrants \\
3 & Microcapsules in all quadrants \\
4 & Microcapsules in all quadrants and clumps of \\
& microcapsules seen \\
\hline
\end{tabular}

\section{RESULTS}

All mice survived to their assigned date of sacrifice without any ill effects noted. No significant inflammation or adhesions were noted in any mouse at laparotomy, including the group who were injected for 48 days. In all mice, the microcapsules were not densely adhered to any peritoneal surfaces. No breakage or change in the structure of the microcapsules was observed.

Alginate microcapsules were present in the peritoneal cavity of 66 of the 81 sacrificed mice (81\%). Within each of the 300-, 600-, and 1200-microcapsule groups, the mean peritoneal quantity score was similar for all volumes of mixing solution. The median of all quantity scores, across all volumes, increased as the number of microcapsules increased. The median scores for the 300-, 600 -, and 1200-microcapsules were 1.0, 2.0, and 4.0, respectively ( $\mathrm{p}<0.0001)$. (Table 2 ) There was no statistical difference in median PMQ score when comparing for the time of implantation. For 300 microcapsules, median score of 1 was noted for 6,12 and 18 days. For 600 microcapsules, median score of 1 for 6 days and 2 for 12 and 48 days were noted. For 1200 microcapsules, median scores of 3, 4 and 4 were noted for 6,12 and 18 days respectively.

No quadrant of the abdomen was observed to sequester the microcapsules more than any other. Small clumps (agglomerations of less than 40 - 50 microcapsules) were noted in some mice who were injected with 1200 microcapsules.

\section{DISCUSSION}

The study provides data on the first step in development of an alginate-microcapsule system to deliver bioengineered cells into the peritoneum following CRS. These data demonstrate that directly injected alginate microcapsules remain distributed throughout the peritoneal cavity of mice over a period of up to 48 days. The most consistently wide distribution was achieved with 1200 microspheres, injected in a volume of $0.5-2.0 \mathrm{~mL}$ of normal saline. The microcapsules did not produce any significant inflammatory reaction, were not adherent to the peritoneum, and produced no ill effects in the injected mice. This suggests that alginate microcapsules 
Table 2. Median peritoneal microcapsule quantification (PMQ) scores.

\begin{tabular}{|c|c|c|c|c|}
\hline Microcapsule number & Injection volume (mL) & $\begin{array}{l}\text { Median PMQ score per } \\
\text { volume group }\end{array}$ & $\begin{array}{l}\text { Median PMQ score per } \\
\text { microcapsule number group }\end{array}$ & $\mathrm{p}$ \\
\hline & 0.5 & 1 & & \\
\hline \multirow[t]{3}{*}{300} & 1.0 & 1 & 1 & Reference \\
\hline & 2.0 & 1 & & \\
\hline & 0.5 & 2 & & \\
\hline \multirow[t]{3}{*}{600} & 1.0 & 1 & 2 & $0.082 *$ \\
\hline & 2.0 & 2 & & \\
\hline & 0.5 & 3 & & \\
\hline \multirow[t]{2}{*}{1200} & 1.0 & 4 & 4 & $<0.0001 \dagger$ \\
\hline & 2.0 & 4 & & \\
\hline
\end{tabular}

${ }^{*}$ Mann-Whitney, compared to 300-microcapsule group; ${ }^{\dagger}$ Mann-Whitney, compared to 300- and 600-microcapsule groups combined.

are a potentially useful tool for the delivery of bioengineered cells into the peritoneum.

Neither the injection volume of normal saline used, nor the dwell time, affected the peritoneal distribution of microcapsules. Higher microcapsule number was the only factor associated with the better widespread distribution. This suggests that a larger number of microcapsules will be needed for even coverage of all abdominal quadrants, but a minimal volume of fluid is required. This may be due to the normal function of the lubricated peritoneum, which has an established ability to distribute fluid, particulate, and cells [11,12]. The findings also suggest that the microcapsules achieve this distribution soon after injection, and maintain it over at least 18 days. This may also be due to the rapid and continual distribution of normal peritoneal fluid.

In the $19 \%$ of mice in which no peritoneal microcapsules were identified, all had received either 300 or 600 microcapsules. In all mice that had 1200 microcapsules injected, all had visualized peritoneal microcapsules on microscopy. This observation may be due to failure to inject sufficient microcapsules at the smaller concentration, and/or failure to visualize the small number of residual microcapsules on microscopy of these groups. Another possible explanation would be incorporation of microcapsules into the peritoneal surface, but given the lack of non-adherent behavior of all observed microcapsules. This is less likely.

The current study demonstrates that alginate microcapsules, injected into the peritoneal cavity, establish and maintain a wide distribution when introduced in sufficient number. Following from these results, the next step in evaluating the usefulness of this delivery and immunoprotective mechanism is to test the distribution and inflammatory reaction to the microspheres when administered at the time of abdominal surgery. The next study is ongoing and is an important next step, given that alginate microcapsules purposefully implanted into the peri- toneum are known to induce a fibrotic reaction [13]. Such an inflammatory response is more likely to occur after abdominal surgery than following transcutaneous injection.

\section{REFERENCES}

[1] Elias, D., Gilly, F., Boutitie, F., Quenet, F., Bereder, J.-M., Mansvelt, B., Lorimier, G., Dubè, P. and Glehen, O. (2010) Peritoneal colorectal carcinomatosis treated with surgery and perioperative intraperitoneal chemotherapy: Retrospective analysis of 523 patients from a multicentric French study. Journal of Clinical Oncology, 28, 63-68. http://dx.doi.org/10.1200/JCO.2009.23.9285

[2] Glehen, O., Gilly, F.N., Boutitie, F., Bereder, J.M., Quenet, F., Sideris, L., Mansvelt, B., Lorimier, G., Msika, S. and Elias, D. (2010) Toward curative treatment of peritoneal carcinomatosis from nonovarian origin by cytoreductive surgery combined with perioperative intraperitoneal chemotherapy: A multi-institutional study of 1290 patients. Cancer, 116, 5608-5618. http://dx.doi.org/10.1002/cncr.25356

[3] Saxena, A., Yan, T.D. and Morris, D.L. (2010) A critical evaluation of risk factors for complications after cytoreductive surgery and perioperative intraperitoneal chemotherapy for colorectal peritoneal carcinomatosis. World Journal of Surgery, 34, 70-78.

http://dx.doi.org/10.1007/s00268-009-0206-0

[4] Koppe, M.J., Boerman, O.C., Oyen, W.J. and Bleichrodt, R.P. (2006) Peritoneal carcinomatosis of colorectal origin: incidence and current treatment strategies. Annals of Surgery, 243, 212-222. http://dx.doi.org/10.1097/01.sla.0000197702.46394.16

[5] Van der Speeten, K., Stuart, O.A., Mahteme, H. and Sugarbaker, P.H. (2010) Pharmacology of perioperative 5-Fluorouracil. Journal of Surgical Oncology, 102, 730735. http://dx.doi.org/10.1002/jso.21702

[6] Venturini, M. (2002) Rational development of capecitabine. European Journal of Cancer, 38, 3-9. http://dx.doi.org/10.1016/S0959-8049(01)00414-2 
[7] Aprile, G., Mazzer, M., Moroso, S. and Puglisi, F. (2009) Pharmacology and therapeutic efficacy of capecitabine: Focus on breast and colorectal cancer. Anticancer Drugs, 20, 217-229.

http://dx.doi.org/10.1097/CAD.0b013e3283293fd4

[8] Marchetti, S., Chazal, M., Dubreuil, A., Fischel, J.L., Etienne, M.C. and Milano, G. (2001) Impact of thymidine phosphorylase surexpression on fluoropyrimidine activity and on tumour angiogenesis. British Journal of Cancer, 85, 439-445. http://dx.doi.org/10.1054/bjoc.2001.1908

[9] Dusseault, J., Leblond, F.A., Robitaille, R., Jourdan, G., Tessier, J., Ménard, M., Henley, N. and Hallé, J.-P. (2005) Microencapsulation of living cells in semi-permeable membranes with covalently cross-linked layers. Biomaterials, 26, 1515-1522. http://dx.doi.org/10.1016/j.biomaterials.2004.05.013

[10] Jourdan, G., Dusseault, J., Benhamou, P.Y., Rosenberg, L. and Hallé, J.P. (2011) Co-encapsulation of bioengineered
IGF-II-producing cells and pancreatic islets: Effect on beta-cell survival. Gene Therapy, 18, 539-545. http://dx.doi.org/10.1038/gt.2010.166

[11] Meyers, M.A. (1973) Distribution of intra-abdominal malignant seeding: Dependency on dynamics of flow of ascitic fluid. American Journal of Roentgenology, 119, 198-206. http://dx.doi.org/10.2214/ajr.119.1.198

[12] Morgan, A., Collier, C. and Kellington, J. (1993) Distribution of glass fibers in the peritoneal cavity of the rat following administration by intraperitoneal injection. Journal of Toxicology and Environmental Health, 38, 245256. http://dx.doi.org/10.1080/15287399309531716

[13] Robitaille, R., Dusseault, J., Henley, N., Desbiens, K., Labrecque, N. and Hallé, J.-P. (2005) Inflammatory response to peritoneal implantation of alginate-poly-L-lysine microcapsules. Biomaterials, 26, 4119-4127. http://dx.doi.org/10.1016/j.biomaterials.2004.10.028 